Teaching and Learning (2009) 5(1), 13-23

\title{
Examining the Use and Success of Demonstration Classrooms that Focus on Differentiated Instruction
}

\author{
TRISHA WOEHRLE \\ Hamilton-Wentworth District School Board \\ MICHELE MOORE \\ Hamilton-Wentworth District School Board \\ JENNIFER GEORGE \\ Hamilton-Wentworth District School Board \\ KAREN HAHN \\ Hamilton-Wentworth District School Board
}

\begin{abstract}
While many teachers currently differentiate their classroom instruction and assessment methods, many others are unsure what differentiation means or how to best support all students in their classroom. Professional development opportunities pursued either individually or as part of a district in-service are available to improve teacher knowledge and build capacity around this important area of practice. Demonstration classrooms, which involve educational professionals observing a classroom teacher offering a differentiated lesson, is one method that can be used to increase teacher knowledge of differentiated instruction and encourage change in teacher practice. The purpose of this paper was to describe the demonstration classrooms within the Hamilton-Wentworth District School Board that were designed to introduce school staff to differentiated instruction and to report on the success of this professional development opportunity.
\end{abstract}

\section{Introduction}

Students enter schools in all shapes and sizes and have different learning needs and ways that they learn best. A 'one size fits all' approach to teaching and learning leaves some students bored and disengaged and others struggling to learn the necessary material (Gregory \& Chapman, 2007). The Report of the Expert Panel on Literacy and Numeracy Instruction for Students with Special Education Needs, Kindergarten to Grade 6 states: "Curriculum tells teachers what to teach, while differentiated instruction tells teachers how to teach it to a range of learners by employing a variety of teaching approaches" (Education for All, 2005, p.14). To meet the needs 
Examining the Use and Success of Demonstration Classrooms that Focus on Differentiated Instruction

and abilities of all students, teachers need to change their practice by differentiating the content (what the students are going to learn), the process (the activities) and/or the product (the accomplishment following a learning period) (Tomlinson, 2004). While some teachers regularly differentiate within their classrooms, others struggle with knowing what differentiation 'looks like' and how to get started.

Research confirms that professional learning communities are an effective method for ensuring teacher professional development, and that continuous, well thought-out collaboration increases the quality of instruction (Dufour, 2004; Eaker, Dufour, \& Dufour 2002; NAESP, 2008). It was this knowledge, paired with a shared vision to make teachers agents of change, that the Hamilton-Wentworth District School Board (HWDSB) embarked upon as an evolution in teacher practice. This paper describes the demonstration classrooms that were offered within one school district over a three-year period. This professional development opportunity focused on improving teacher understanding of differentiated instruction and the use of various techniques, approaches and/or strategies in their classroom. The success of this new professional development opportunity was assessed and is also shared within this report.

HWDSB's Demonstration Classrooms on Differentiated Instruction

Demonstration classrooms focusing on differentiated instruction were first initiated by HWDSB's Special Education Department during the 2005/06 school year in response to the Council of Ontario Directors (CODE) Education for All Project. This one-time, half-day professional development opportunity originally provided attendees with the opportunity to view a colleague demonstrating differentiated instructional strategies in their classroom. The format of the sessions during the 2005/06 and 2006/07 school years involved the demonstration class teacher meeting with the participants (usually four to five HWDSB staff members) prior to the lesson to discuss the purpose of differentiated instruction, provide an introduction to the lesson and to give the observers a brief background of the students in the class. The attendees then had the opportunity to watch a lesson that incorporated differentiated instruction approaches and strategies. Following the lesson, a debriefing session was held to allow participants to dialogue about the lesson and for the lead teacher to answer any questions the observers had. 
Examining the Use and Success of Demonstration Classrooms that Focus on Differentiated Instruction

During the 2005/06 school year, participants had the opportunity to view a demonstration class (either a primary or junior lesson) during a two-month window. The focus of the lessons was introducing attendees to differentiated instruction and the type and availability of assistive technology within the school district. Nearly 100 HWDSB staff participated in this professional development opportunity. During the 2006/07 school year, six demonstration classrooms (in grades 2, 5, and 7) were established and each classroom offered six observable differentiated instruction lessons that focused on language. Approximately 150 HWDSB staff participated during this school year.

During the 2007/08 school year, a Special Assignment Teacher position was created with the following objectives in mind:

- $\quad$ planning and delivering professional development based on the Education for All recommendations in the areas of Differentiated Instruction in Grades JK to 8

- working with all schools to promote Differentiated Instruction and to identify best practices

- working with schools to ensure the ongoing sustainability of current Differentiated Instruction projects

- providing leadership and support to the System Learning Community Day Committee with regard to Differentiated Instruction

- working in a variety of school settings and classrooms to demonstrate individual and group strategies and technological supports for students with an emphasis on Differentiated Instruction and assessment for learning

- working to promote collaboration for Differentiated Instruction between schools in the Grade 8 to 9 transition process

This teacher was also responsible for the organization of five demonstration classrooms (primary, junior, intermediate levels). The decision to move to a divisional approach permitted 
Examining the Use and Success of Demonstration Classrooms that Focus on Differentiated Instruction

teachers to approach differentiation as a strategy that works for learners, rather than a grade specific approach. Each classroom offered four observable differentiated instruction lessons. Lessons taught by hosting classroom teachers were firmly framed by recommendations of Education for All The Report of the Expert Panel on Literacy and Numeracy Instruction for Students With Special Education Needs, Kindergarten to Grade 6 (2005). Topics included classroom management, assessment (conferencing, self/peer) and assistive technology (graphic organizers). During the 2007/08 school year, the demonstration classroom observation also became a two-part professional development opportunity. Part-one of the session was similar to the format used during the first two years where attendees were invited to observe a colleague using differentiated instructional strategies in their classroom. Following the lesson and the debriefing session, participants were encouraged to try the differentiated instruction strategies within their own classrooms. During part-two of this in-service, all observers from the sessions met to discuss their experiences and share their key learning. Teachers were also given access to an online conference where they were able to access differentiated materials, encouraged to post questions, as well as share resources and success stories with colleagues. Almost 100 teachers participated in this professional development opportunity during the 2007/08 school year.

Within the debriefing sessions during the first two years, attendees were asked to complete a survey about their observation and indicate their level of satisfaction with the session and overall value to professional development. The observers were also asked to comment on what they learned and what skills, strategies, or activities they planned to take back to their classroom. The survey used in the third year of this project, when the demonstration classrooms became a twopart session, was more detailed and examined participant comfort level with differentiated instruction and assistive technology, as well as collected participant satisfaction with the twopart program.

The next section of this paper presents a summary of the findings from all demonstration classroom participants followed by the combined findings for participants during the first two years of this project. The third year survey findings are reported separately. 
Examining the Use and Success of Demonstration Classrooms that Focus on Differentiated Instruction

\section{Evaluating the Success of the Demonstration Classrooms}

Over the three school years, over 300 HWDSB staff observed a demonstration classroom. A total of 306 attendees completed and returned a survey about their experiences with their observation.

According to the survey responses, professionals from a variety of different roles observed the demonstration classroom (see Table 1). As displayed within the table, the majority of observers were classroom teachers, specifically primary and junior teachers; however, consultants, learning resource teachers, student and occasional teachers also attended. The participants reported having 1 (first year of teaching) to 35 years of teaching experience with an average of approximately six years. The observers had worked in their schools or current role from 1 to 22 years with an average of approximately five years.

Table 1: Survey Respondents

\begin{tabular}{|c|c|c|}
\hline $\begin{array}{c}\text { Year } 1 \\
(2005 / 06 \text { School Year })\end{array}$ & $\begin{array}{c}\text { Year } 2 \\
(2006 / 07 \text { School Year })\end{array}$ & $\begin{array}{c}\text { Year } 3 \\
\text { (2007/08 School Year) }\end{array}$ \\
\hline $\begin{array}{l}\text { - } 41(43 \%) \text { primary teachers } \\
\text { - } 44(46 \%) \text { junior teachers } \\
\text { - } 5(5 \%) \text { special education } \\
\text { consultants } \\
\text { - } 3(3 \%) \text { student teachers } \\
\text { - } 2(2 \%) \text { learning resource teachers } \\
\text { - } 1(1 \%) \text { administrator }\end{array}$ & $\begin{array}{l}\text { - } 61(42 \%) \text { primary teachers } \\
\text { - } 40(27 \%) \text { junior teachers } \\
\text { - } 19(13 \%) \text { intermediate teachers } \\
\text { - } 11(7 \%) \text { learning resource teachers } \\
\text { - } 5(3 \%) \text { student teachers } \\
-5(3 \%) \text { junior/intermediate teachers } \\
\text { - } 2(1 \%) \text { special education } \\
\text { consultants } \\
\text { - } 2(1 \%) \text { special class teachers } \\
-1(1 \%) \text { ESL teacher } \\
-1(1 \%) \text { secondary school teacher }\end{array}$ & $\begin{array}{l}\text { - } 26(41 \%) \text { primary teachers } \\
\text { - } 20(32 \%) \text { junior teachers } \\
\text { - } 1(4 \%) \text { primary/junior teacher } \\
\text { - } 8(13 \%) \text { intermediate teachers } \\
\text { - } 2(3 \%) \text { learning resource teachers } \\
\text { - } 3(4 \%) \text { special class teachers } \\
\text { - } 1(4 \%) \text { core French teacher } \\
\text { - } 1(4 \%) \text { French Immersion teacher } \\
\text { - } 1(4 \%) \text { long-term occasional } \\
\text { teacher }\end{array}$ \\
\hline
\end{tabular}

Respondents were asked about the type of differentiation that they observed during their visit. Participants could view more than one form of differentiation during their session. As displayed in Table 2, consistently across all three school years, most participants reportedly observed differentiation based on student ability, while fewer respondents viewed differentiation based on student interest or learning preference. 
Examining the Use and Success of Demonstration Classrooms that Focus on Differentiated Instruction

Table 2: Type of Differentiation Observed

\begin{tabular}{|l|r|r|r|}
\hline & \multicolumn{1}{|c|}{$\begin{array}{c}\text { Year 1 } \\
(\mathbf{2 0 0 5} / \mathbf{0 6})\end{array}$} & $\begin{array}{c}\text { Year 2 } \\
(\mathbf{2 0 0 6 / 0 7})\end{array}$ & $\begin{array}{c}\text { Year 3 } \\
(\mathbf{2 0 0 7 / 0 8})\end{array}$ \\
\hline Differentiation based on student ability & $86(90 \%)$ & $132(89 \%)$ & $62(98 \%)$ \\
\hline Differentiation based on student interest & $28(29 \%)$ & $69(47 \%)$ & $28(44 \%)$ \\
\hline Differentiation based on student learning preference & $18(19 \%)$ & $59(40 \%)$ & $27(43 \%)$ \\
\hline Differentiation based on content & $48(50 \%)$ & $69(47 \%)$ & $36(57 \%)$ \\
\hline Differentiation based on process & $75(78 \%)$ & $95(64 \%)$ & $39(62 \%)$ \\
\hline Differentiation based on product & $68(71 \%)$ & $86(58 \%)$ & $31(49 \%)$ \\
\hline
\end{tabular}

Survey Findings for the 2005/06 (Year 1) and 2006/07 (Year 2) School Years

The observers of the demonstration classroom were asked, on a five-point scale, about their level of comfort with using differentiated instruction and assistive technology before and after they observed the differentiated instruction lesson. Comfort levels for both questions improved significantly. For differentiated instruction, respondents provided an average score of 3.05 prior to their observation and 4.08 after their observation. This represents a significant improvement $(t=12.64, \underline{p}<.05)$ in their level of comfort with differentiated instruction. For assistive technology, respondents provided an average score of 3.09 prior to their observation. The average score increased to 3.80 after their observation. This represents a significant improvement $(t=9.16, \underline{p}<.05)$ in their comfort level with assistive technology.

The observers were asked to describe their key learning from their observation. Several respondents noted how easily differentiated instruction could be facilitated within their classroom and "how simply the needs of the class can be met." Respondents learned about the different ways that students could be grouped together, that groupings can change when activities change, and how to plan lessons using groups so each group could work on a task according to their ability. Observers also learned how to plan and implement different learning centres and the importance of targeting different learning styles and incorporating them into assigned tasks. 
Examining the Use and Success of Demonstration Classrooms that Focus on Differentiated Instruction

Various forms of assistive technology (such as 'Clicker' and 'Co-writer') were introduced to observers during the lesson. Observers learned about some of the tools that were available within the school district and the importance of using these tools to increase student engagement and learning. Some of the observers thought that the "students appear to be more on task when given work at their level and ability." Observers also learned how to pre-assess students, how to focus on one idea but obtain different products, and the benefit of using 'exit cards'. One observer wrote: "I had heard about exit cards but seeing it used makes me feel comfortable now to try it." One of the main learnings provided from several respondents was that "You can't do differentiated instruction for everything. Take it one step at a time."

The observers also listed many skills, strategies and/or activities that they planned to try in their classroom. The list included the following: various student grouping strategies, opportunities or activities for different learning styles, more hands-on activities to demonstrate learning, entry and exit cards, group leaders to ensure instructions are read and understood, provide assistive technology computer software for students to use, use of centres (such as listening centres for struggling readers), anchor activities, as well as encouraging student evaluation and assessing students based on their ability.

After the first year of this professional development opportunity, the lead teachers met to share their experiences with the Demonstration Classrooms and to discuss the plan for the following year. During their discussion, the teachers commented on how much more they had learned about differentiated instruction through opening up their classrooms to other teachers. Differentiated instruction had become more embedded in their own practice and they had developed a larger repertoire of ideas and materials. They also commented on the academic growth of their students, the increased engagement of students during the lessons, and the decreased behavioural issues in their classrooms. Several teachers also shared some of the comments that they had received from parents about their child's increased interest and enjoyment of school. The demonstration class experience not only allowed these teachers to share their talents with others in our system, but also allowed for personal growth in the area of differentiated instruction. 
Examining the Use and Success of Demonstration Classrooms that Focus on Differentiated Instruction

\section{Survey Findings for the 2007/08 (Year 3) School Year}

As noted earlier, demonstration class participants were asked to complete a more detailed survey during the 2007/08 school year. A total of 63 participants completed and returned a survey. The observers of the demonstration class were asked, on a five-point scale, about their familiarity with the term differentiated instruction before and after participating in the demonstration class opportunity. Familiarity with this term showed significant improvement, average scores increased from 3.56 to $4.48(t=10.79, \underline{p}<.05)$. Respondents also showed significant improvement in their reported comfort level with using differentiated instruction in their classroom. Prior to their observation, respondents provided an average score of 2.94 (on a five point scale), while after the observation the average score increased to $4.07(t=13.83, \underline{p}<.05)$.

Demonstration class participants were asked how often they used various principles of differentiated instruction, how often they used various strategies and their comfort level with each before and after participating in the demonstration class in-service. Table 3 presents the number and percentage of respondents who indicated that they used the approach or strategy either 'frequently' or 'always'. The comfort level is based on a five-point scale; the average score is provided. As displayed below, the frequency of use (either frequent or always), as well as the comfort level with all of the principles and strategies, increased from the beginning to the end of this professional development opportunity, and significant improvement was noted in the comfort level for all strategies listed.

Table 3: Frequency of Use and Comfort with Various DI Principles and Strategies

\begin{tabular}{|l|r|r|r|r|}
\hline & \multicolumn{1}{|c|}{$\begin{array}{c}\text { Frequency of use } \\
\text { ('frequent' or 'always') }\end{array}$} & \multicolumn{1}{|c|}{ Comfort Level } \\
\hline & \multicolumn{1}{|c|}{ Pretest } & \multicolumn{1}{c|}{ Posttest } & \multicolumn{1}{c|}{ Pretest } & \multicolumn{1}{c|}{ Posttest } \\
\hline Respectful Tasks & $28(45 \%)$ & $38(62 \%)$ & 3.32 & 4.00 \\
\hline Flexible Groupings & $28(45 \%)$ & $45(71 \%)$ & 3.41 & 3.94 \\
\hline Ongoing assessment and adjustment & $40(63 \%)$ & $51(81 \%)$ & 3.45 & 3.97 \\
\hline Differentiate content & $19(30 \%)$ & $39(62 \%)$ & 3.08 & 3.69 \\
\hline Differentiate process & $25(40 \%)$ & $45(71 \%)$ & 3.42 & 4.00 \\
\hline Differentiate product & $23(37 \%)$ & $41(65 \%)$ & 3.18 & 3.94 \\
\hline Assistive Technology & $8(13 \%)$ & $17(27 \%)$ & 2.82 & 3.29 \\
\hline
\end{tabular}


Examining the Use and Success of Demonstration Classrooms that Focus on Differentiated Instruction

Similar to the survey used in the previous years, participants were asked to share their key learnings from their participation in the two-part demonstration class opportunity. Similar comments were obtained, such as learning about the various ways to group students, that differentiation can occur in various stages in the instructional process, it is possible to differentiate the project, not just the process or content, and strategies to improve student engagement in the assigned task. The observers also appreciated learning about "what differentiated instruction looks like in a classroom" and were provided with classroom management ideas for students who completed the assigned tasks.

Participants also described the many skills, strategies and/or activities that they tried in their classrooms between the first and second sessions. The list included: pre-assessment and creating groups based on learning needs, flexible groupings, providing choice in assignments, word walls, literature circles, extension activities and introducing assistive technology to support students with their writing needs. While most teachers felt that the strategies 'worked well' in their classroom, some challenges were noted. Survey respondents identified the challenge of finding time to plan for the lesson and locating required resources (e.g., appropriately leveled books on $\mathrm{CD}$ for struggling readers). Ensuring that the assignments were challenging enough for all learners was expressed as well as having tasks that were not too challenging, especially for children with special learning needs. Some teachers noted a lack of cooperation between students within some groups, student absenteeism or students being unprepared for class. When asked about 'next steps,' most of the survey respondents were optimistic and planned to continue differentiating their lessons. Some of the responses included: "I will keep trying and refining my skills," "continue to implement new ideas," and "keep working at it. Planning takes a lot of time and finding resources." Suggestions for additional support and resources were mainly regarding the need for planning time, as well as additional resources that would support their lessons and the diverse learners in their classrooms.

The final section of the survey asked participants about their overall satisfaction with this professional development opportunity. On a five point scale, the respondents provided an average score of 4.65 for satisfaction with their observation of the demonstration class and 4.31 for the opportunity to try the activity or strategy observed in the class. An average score of 4.79 
Examining the Use and Success of Demonstration Classrooms that Focus on Differentiated Instruction

was given for the value to their professional development and 4.70 as the value of being part of a professional learning community surrounding demonstration classrooms. The majority of participants $(n=58,94 \%)$ preferred the two-session professional development opportunity while the remaining respondents had no comment. The final question of the survey asked the participants to provide any other comments they had about their visit to the demonstration class. Many positive comments were provided such as "excellent," "worthwhile," "very useful," and "make it open to more teachers." Comments about the demonstration class teachers were also provided. For example: "It was an amazing opportunity to see what a dedicated professional can do with D.I." Respondents enjoyed the two-part in-service opportunity. They believed that it was "a great way to learn the principles of DI," and "It was great being able to actually observe a real teacher in her classroom. Learned a lot in the second meeting by sharing and discussing with my peers." Some respondents also provided suggestions for improvement such as providing more intermediate level ideas and needing more time (perhaps a half-day) to reflect on process, make changes and implement the new ideas in the classroom.

\section{Summary}

The HWDSB's Special Education Department continues to be a pioneer in the field of differentiation, working with teachers, administrators, educational assistants and students towards a common understanding that 'what is good for some, is essential for some.' While many professional development opportunities and supports for differentiated instruction are available to HWDSB staff, the three year demonstration classroom observation provided educational professionals with the opportunity to witness differentiation in 'action!' During the first two years district staff were invited to observe a lesson and debrief with the classroom teacher about their observations and learning. The third year saw the professional development opportunity expand to a two-session meeting, which not only allowed the attendees to observe a lesson and debrief with the teacher, but also to try out differentiation in their own classroom and share their personal experiences with other participants. Additional support was also provided through an internal electronic conference where attendees could pose questions and/or share experiences. The success of this professional development opportunity was measured through the collection of survey data. The findings were positive with improvements noted in teacher knowledge about differentiated instruction and comfort with trying the new approaches or 
Examining the Use and Success of Demonstration Classrooms that Focus on Differentiated Instruction

strategies in their classroom. The attendees also shared a key learning and the many strategies or activities that they planned to try or did try in their classroom. The demonstration classrooms within the HWDSB proved to be a valuable method in introducing educational professionals to differentiated instruction and encouraging educators to slowly change their classroom practice.

\section{References}

Dufour, R. (2004). What is a professional learning community? Educational Leadership, 61 (8), 6-11.

Eaker, R., Dufour, R., \& Dufour, R.(2002). Getting started: Reculturing schools to become professional learning communities. Bloomington: National Educational Service.

Gregory, G. \& Chapman, C. (2007). Differentiated instructional strategies. Thousand Oaks: Corwin Press.

National Association of Elementary School Principals (NAESP) (2008). Leading learning communities: standards for what principals should know and be able to do. Alexandria, VA: Collaborative Communications Group.

Ontario Education (2005). Education for all: The report of the expert panel on literacy and numeracy instruction for students with special education needs, kindergarten to grade 6. Toronto: Queen's Printer of Ontario. 